\title{
Asian American
}

National Cancer Institute

\section{Source}

National Cancer Institute. Asian American. NCI Thesaurus. Code C16310.

Denotes a person having origins in any of the original peoples of the Far East, Southeast Asia, or the Indian subcontinent, and who was either born in the United States or who was naturalized as a citizen of the United States. 